\title{
Congenital absence of aortic and pulmonary valve in a fetus with severe heart failure
}

\author{
Jan Marek, Jan Škovránek, Viera Povýšilová
}

Kardiocentrum,

University Hospital

Motol, Prague, Czech

Republic

J Marek

J Skovránek

Department of

Pathology, Second

Medical School,

Prague, Czech

Republic

V Povýšilová

Correspondence to:

Dr J Marek, Kardiocentrum,

University Hospital Motol

15018 Prague, Czech

Republic. 18 July 1995
Charles University,

Accepted for publication

\begin{abstract}
A case of congenital absence of both aortic and pulmonary valves with severe heart failure detected prenatally by crosssectional and pulsed and colour Doppler echocardiography is reported in small for gestational age male fetus in 17 th week of gestation. Additional double outlet right ventricle, hypoplastic left ventricle, and ventricular septal defect, as well as multiple extracardiac anomalies, were found by prenatal echocardiographic investigation and confirmed by necropsy examination. Retrograde diastolic Doppler waveforms retrieved from pulmonary artery, aorta, and umbilical arteries revealed massive insufficiency throughout both the great arteries, which eliminated diastolic placental perfusion, documented by absent anterograde diastolic flow in the umbilical vein. These prenatal echocardiographic findings may contribute to an understanding of the mechanism of rapid and progressive heart failure and growth retardation in the fetus. Severe cardiac failure may explain why congenital aplasia of both the aortic and the pulmonary valves has not been described postnatally, and only two
\end{abstract}

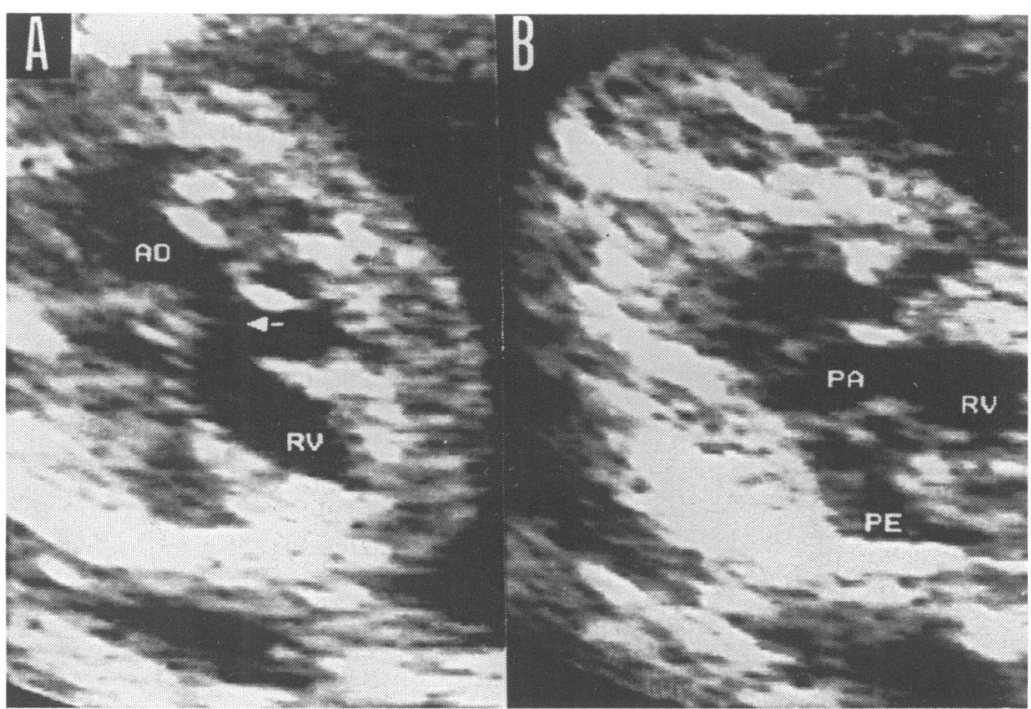

Figure 1 Cross sectional echocardiography showing the origin of the aorta $(A O)$ from the right ventricle $(R V)$. Ventricular septal defect (arrow) was seen close to the aorta $(A)$. Pulmonary artery $(P A)$ also originates from the right ventricle $(B)$ and no semilunar leaflets were visualised. A pericardial effusion (PE) behind the right ventricle was evident. fetal cases revealed by necropsy have been published.

(Heart 1996;75:98-100)

Keywords: absent aortic valve; absent pulmonary valve; fetal echocardiography; heart failure

Congenital absence of both semilunar valves in separated great arteries is an exceedingly rare heart malformation. The only reported examples are described by Hartwig et al, ${ }^{1}$ who found congenital absence of semilunar valve leaflets in complex congenital heart defects in two fetal necropsy examinations. Here we describe a case of severe heart failure in a fetus with absence of both aortic and pulmonary valves, revealed by fetal echocardiographic examination in the 18th week of gestation.

\section{Case report}

A 33 year-old healthy gravida 2, para 1 was referred for detailed fetal cardiovascular evaluation at week $17+4$ of gestation for a small for gestational age fetus with hydrocephaly, hydrothorax, ascites, and heart malformation, suspected from cardiomegaly and abnormal

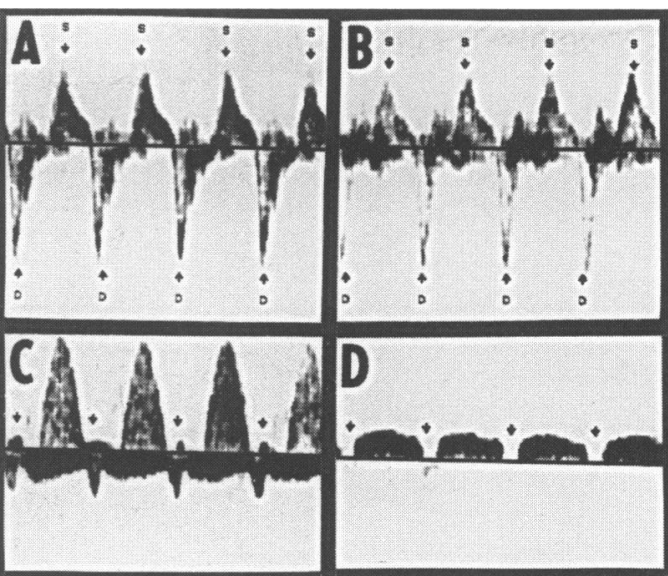

Doppler flow patterns retrieved from the ascending aorta $(A)$ and main pulmonary artery (B) show the systolic antegrade (s) and diastolic retrograde (D) flows.

Simultaneous Doppler from the umbilical artery and vein (C) indicates reverse diastolic arterial waveform (arrows). Absent prograde diastolic flow in umbilical vein

(D) (arrows) is better documented separately. 


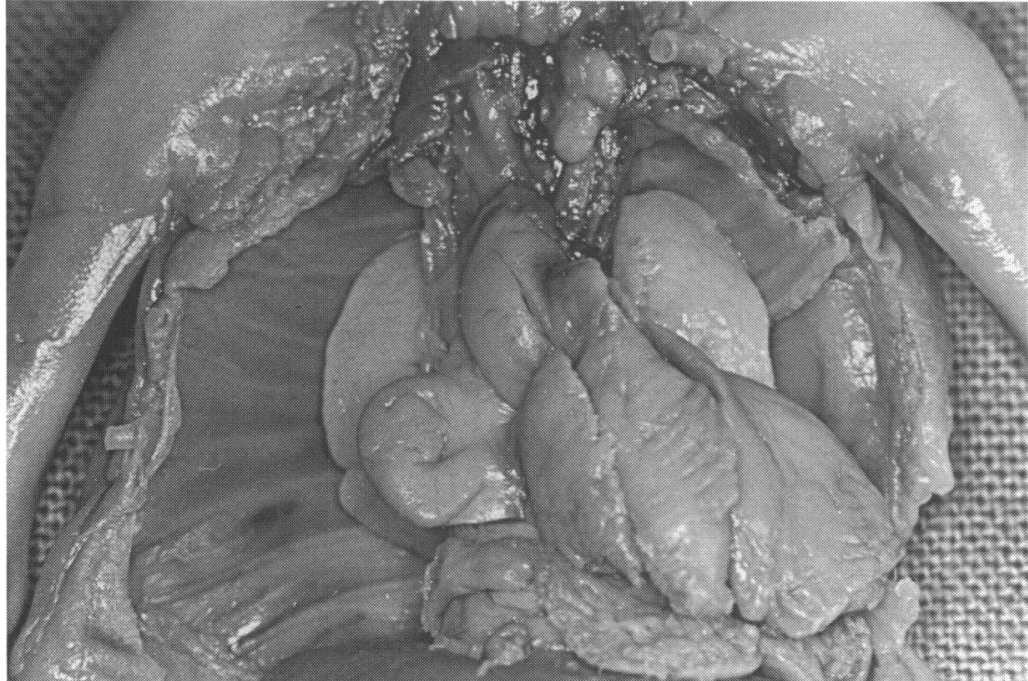

Figure 3 Double outlet right ventricle with d-malposed side by side great arteries at necropsy. four chamber view on routine ultrasound examination.

Cross sectional echocardiography and pulsed Doppler/colour flow mapping examination was performed using $5.0 \mathrm{MHz}$ annular array and $3.5 \mathrm{MHz}$ phased array transducers (Ultramark 9, ATL). The investigation revealed hydrops, pericardial effusion, cardiomegaly (cardiothoracic index 0.90 ), and complex congenital heart malformation: situs solitus viscera and atria, atrioventricular concordance with small left atrium (non-

\section{Figure 4 Aorta (ao)} viewed through right ventricular (rv) approach. Shallow ventriculo-aortic endothelial junction with no evidence of semilunar leaflets (arrow). Coronary ostia in normal position (asterisk).
Figure 5 Pulmonary artery ( $p a)$ originates from the right ventricle ( $r v$ ) with several attachments of dysplastic tricuspid valve (tv). Only a small endothelial narrowing with aplasia of semilunar leaflets was seen at the ventriculo-pulmonary junction (arrow).
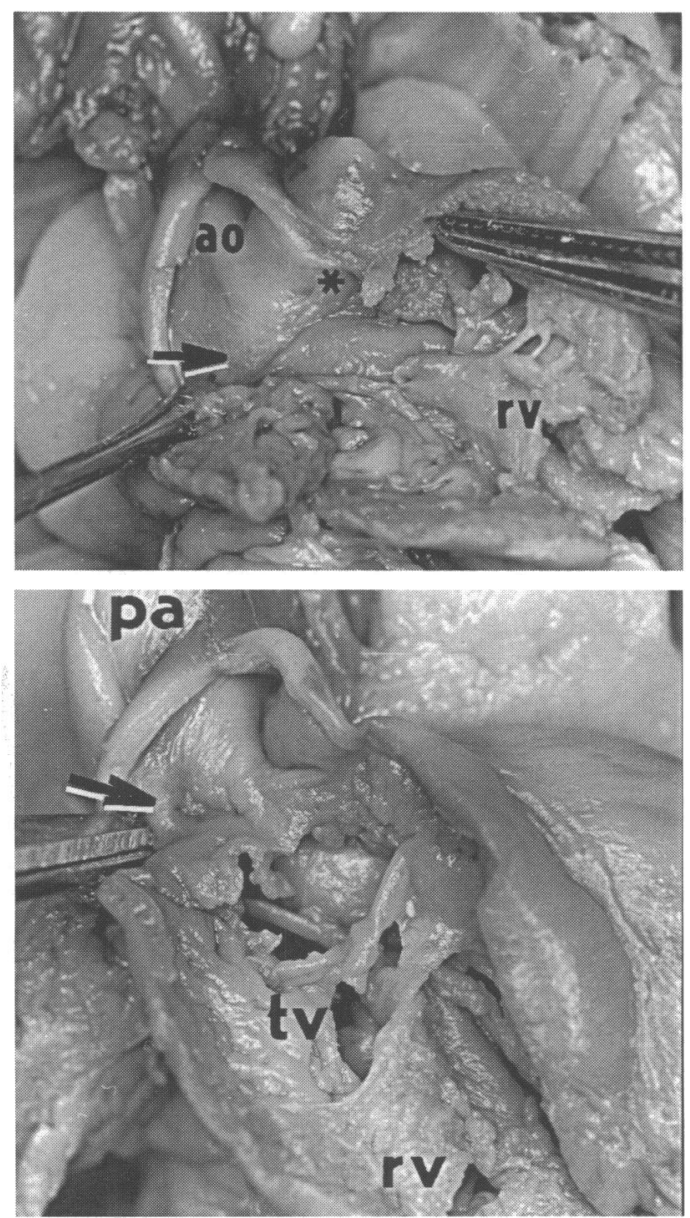

restrictive foramen ovale), hypoplastic mitral orifice (mitral/tricuspid ratio $0 \cdot 65$ ), and small left ventricle (dimension $65 \%$ of normal value). Double outlet right ventricle with $d-$ malposition, side by side great arteries, and a large subaortic ventricular septal defect were observed (fig 1). Moderate tricuspid regurgitation was detected by colour flow mapping.

The great arteries were normal in size. No evidence of semilunar valves was found in either the aorta or the pulmonary artery. Colour flow mapping and pulsed Doppler revealed antegrade systolic and retrograde diastolic flow patterns in the great arteries (fig 2). The estimated regurgitation fraction was close to $100 \%$. Reverse diastolic flow was also detected in the umbilical arteries. Umbilical vein Doppler sampling showed absent diastolic flow (fig 2).

The family was counselled and pregnancy was terminated by prostaglandin infusion. Necropsy examination revealed a $45 \mathrm{~g}$ male fetus (expected weight at 18 weeks amenorrhea is $120 \mathrm{~g}$ ). Total length was $15 \mathrm{~cm}$ and crown-rump length $10 \mathrm{~cm}$. Macroscopic observation confirmed the presence of a complex heart anomaly, with double outlet right ventricle, hypoplastic left atrium, mitral orifice and left ventricle, and d-malposed side by side great arteries (fig 3). The ventricular septal defect was classified as large remote with close attachment of a dysplastic tricuspid valve. Foramen ovale was widely opened and the ductus arteriosus was found to be patent.

The ventriculo-aortic and ventriculo-pulmonary endothelial junction formed flat ridges, apparently without functional organisation (fig 4,5). The coronary ostia and arteries were normal. Besides this, multiple additional extracardiac anomalies were found: hydranencephaly (hemispheric brain aplasia), hypoplastic left forearm with absence of the left hand, right sided radial aplasia (clubhand), and low set ears.

\section{Discussion}

There are many published reports on congenital absence of the pulmonary valve. The prenatal diagnosis of this anomaly is rare, but feasible. $^{23}$ Congenital absence of the pulmonary valve probably does not have a significant impact on fetal cardiovascular circulation and fetal development; however, prenatal diagnosis allows early counselling and planning of prompt care after delivery.

Congenital absence of the aortic valve is an extremely rare heart malformation. Only seven cases have been reported so far. ${ }^{45}$ The absent aortic valve is associated with other structural heart malformations in all instances. In all but one patient the diagnosis was made postnatally. Bierman and colleagues described the antenatal and postnatal echocardiographic features of congenital absence of the aortic valve. They also found retrograde diastolic waveforms in the thoracic aorta, but they did not perform Doppler examination of the umbilical vessels. All seven patients in their report died of heart failure without surgical intervention. 
Published cases of absent aortic and pulmonary valve

\begin{tabular}{|c|c|c|c|c|c|}
\hline $\begin{array}{l}\text { Case } \\
\text { no }\end{array}$ & Detected at & $\begin{array}{l}\text { Age of } \\
\text { gestation } \\
\text { (amenorrhoeal } \\
\text { biometry [weeks]) }\end{array}$ & Sex & $\begin{array}{l}\text { Additional } \\
\text { heart malformation }\end{array}$ & Extracardiac anomaly \\
\hline $1^{\star}$ & Fetal necropsy & $18 / 13$ & $\mathbf{M}$ & $\begin{array}{l}\text { DORV, MA, HLV, } \\
\text { d-MGA, VSD subAo, } \\
\text { STRD-TV }\end{array}$ & $\begin{array}{l}\text { Hypoplastic nose, bilateral radial } \\
\text { aplasia, bilateral absence of the } \\
\text { thumb, absence of the left index } \\
\text { finger, malrotation of the intestines, } \\
\text { horseshoe kidney }\end{array}$ \\
\hline $2^{\star}$ & Fetal necropsy & $18 / 12$ & $\mathbf{M}$ & HLV, VSD subAo & $\begin{array}{l}\text { Cleft lip and palate on the right, } \\
\text { low set ears, incomplete fusion } \\
\text { at the scrotal swellings }\end{array}$ \\
\hline $3+$ & $\begin{array}{l}\text { Fetal } \\
\text { echocardiography }\end{array}$ & $17 / 15$ & $\mathbf{M}$ & $\begin{array}{l}\text { DORV, HLV } \\
\text { d-MGA, VSD remote, } \\
\text { dysplastic TV }\end{array}$ & $\begin{array}{l}\text { Hydranencephaly (hemispheric brain } \\
\text { aplasia), hypoplastic left forearm with } \\
\text { absence of the left hand, rightsided } \\
\text { radial aplasia (clubhand), low set ears }\end{array}$ \\
\hline
\end{tabular}

d-MGA, d-malposition of the great arteries; DORV, double outlet right ventricle; HLV, hypoplastic left ventricle; M, male; MA, mitral atresia; STRD-TV, straddling of the tricuspid valve; TV, tricuspid valve; VSD subAo, subaortic ventricular septal defect. $\star$ Hartwig et al

tThis publication.

The only report of congenital absence of both the aortic and the pulmonary valve was by Hartwig and associates, ${ }^{1}$ from a necropsy examination of two fetuses which died in utero before the 18th week of pregnancy. Both were small for gestational age and had complex congenital defects and additional extracardiac malformations (table).

The authors assumed that both the fetuses died of cardiac failure. Our fetal findings confirm this suggestion. Doppler flow patterns retrieved from the aorta, pulmonary artery, and umbilical vessels showed gross regurgitation throughout both great arteries which eliminated diastolic placental perfusion and resulted in severe heart failure and fetal growth retardation. Severe cardiac failure causing early fetal death may explain why congenital aplasia of both the aortic and the pulmonary valve is not described postnatally.

In the absence of an aortic valve the regurgitation volume is obviously smaller and therefore does not cause early fetal heart failure, although in the only published case of fetally diagnosed aplasia of the aortic valve ascites was noted. In cases with absence of the pulmonary valve, a hypoplastic annulus or right ventricular outflow tract, together with ventricular hypertrophy, will usually reduce retrograde diastolic blood volume. In absent pulmonary valve with arterial duct agenesis ${ }^{6}$ retrograde aortic run-off is not possible.

The pathogenesis of the absence of both semilunar valves is unknown. All three cases described were male, as were a further seven reported cases of absent aortic valve. One can speculate that $\mathrm{X}$ linked recessive inheritance or other $\mathrm{X}$ linked factors may play a role in the maldevelopment of the endocardial cushion tissue at the ventriculo-aortic junction. Unfortunately, none of these 10 cases underwent chromosomal evaluation.

Note added in proof: During the preparation of this paper we found a report of two other fetuses with absent aortic and pulmonary valve: Miyabara S, et al. Heart Vessels 1994;9:49-55.

Supported by grant No 2038-3 from Czech Ministry of Health. The authors are grateful to Mr Vlastimil Stárek for photographs.

1 Hartwig NG, Vermeij-Keers $\mathrm{Ch}$, De Vries $\mathrm{HE}$ Gittenberger-De Groot AC. Aplasia of semilunar valve leaflets: two case reports and developmental aspects. Pediatr Cardiol 1991;12:114-7.

2 Fouron J-C, Sahn DJ, Bender R, Block R, Schneider H, Fromberger $\mathrm{P}$, et al. Prenatal diagnosis and circulatory characteristics in tetralogy of Fallot with absent pulmonary valve. $A m \neq$ Cardiol 1989;64:547-9.

3 Rein AJTT, Singer $R$, Simcha A. Prenatal diagnosis of tetralogy of Fallot with absence of the leaflets of the pulmonic valve. Int $\mathcal{F}$ Cardiol 1992;34:211-3.

4 Bierman FZ, Yeh M-N, Swersky S, Martin E, Wigger JH Fox $H$. Absence of the aortic valve: Antenatal and postnox $H$. Absence of the aortic valve: Antenatal and postfeatures. $¥ \mathrm{Am}$ Coll Cardiol 1984;3:833-7.

$5 \mathrm{Lin}$ AE, Chin AJ. Absent aortic valve: complex anomaly. Pediatr Cardiol 1990;11:195-8.

6 Emmanouilides GC, Thanapoulos B, Siassi B, Fishbein M "Agenesis" of ductus arteriosus associated with the syndrome of tetralogy of Fallot and absent pulmonary valve. Am $\mathcal{F}$ Cardiol 1976;37:403-9. 